\title{
Context matters: Heads of Department's leadership practices in monitoring and supporting teachers in schools participating in Jika iMfundo
}

\section{C.C. Nonhlanhla Mthiyane}

School of Education, Durban University of Technology, Pietermaritzburg, South Africa Cynthiam@dut.ac.za (corresponding author)

https://orcid.org/0000-0003-0547-3221.

\section{Jaqueline Naidoo}

School of Education, University of KwaZulu-Natal, Pietermaritzburg, South Africa naidooj@ukzn.ac.za

https://orcid.org/0000-0001-9084-3818

\section{Carol Bertram}

School of Education, University of KwaZulu-Natal, Pietermaritzburg, South Africa

BertramC@ukzn.ac.za

http://orcid.org/0000-0002-2961-5645

(Received: 11 September 2018; accepted: 10 April 2019)

\section{Abstract}

Jika iMfundo, with its particular focus on curriculum coverage, is an intervention for systemic education change. In this paper we focus on the extent to which Heads of Departments (HoDs) are able to play an adaptive leadership role in supporting the teachers in their departments. We report on data generated from interviews with HODs in fifteen KwaZulu-Natal schools that had been part of the Jika iMfundo intervention from 2015 to 2017. While Jika iMfundo's aim is to shift HODs' leadership practices from being based on technical compliance to the achievement of a more developmental and supportive role, our findings show that the majority of HODs were not able to do this because of their heavy workloads and overwhelming administrative responsibilities. We argue that the theory of change based on the Programme for Improving Learning Outcomes (PILO) has unrealistic expectations of HODs as key levers of change for curriculum coverage and, furthermore, that this theory does not take into account the realities and variations of resourcing in different school contexts.

Keywords: curriculum coverage, Jika Imfundo, adaptive leadership, heads of departments, curriculum tracking, Programme for Improving Learning Outcomes 


\section{Introduction}

Jika iMfundo, an intervention for systemic education change, has a particular focus on teachers' improvement in curriculum coverage. It was developed by PILO working in partnership with the KwaZulu-Natal Department of Education. It was implemented as a pilot project from 2015 to 2017 in two education districts, one largely rural (King Cetshwayo) and one more urban (Pinetown). One aspect of the Jika iMfundo project is the training of School Management Teams (SMTs) which consist of principals, deputy principals, and HODs. All members of the SMTs are required to attend workshops on Management and leadership (Module 1); Effective curriculum supervision—building relationships to improve learning (Module 2); and Leading instruction in schools (Module 3). Jika iMfundo adopts an "adaptive leadership framework" which requires that SMT members to "enter an adaptive change space" (Leadership and Management Module 1, p. 3), taking the stance of problem solving, rather than that of a technical approach to change where this is driven by external factors and involves simply following a series of steps.

The findings show that many HODs found that Jika iMfundo tools and workshops were helpful in clarifying their roles. However, they also reported that administrative requirements are burdensome, and that Jika iMfundo adopts a one-size-fits-all approach that overlooks the variations in learners' readiness to learn at the level expected by the curriculum, as well as contextual factors which have an impact on HODs' ability to perform their supervisory and supportive roles. Our main argument is that the schools' former administrative department (Department of Education and Training, House of Assembly or House of Delegates) is a key variable in determining the HODs' ability to support teachers in their department in a flexible way, rather than approaching support and monitoring in a technical way.

\section{The role of HODs in South African schools}

The Personnel Administrative Measures (PAM) document issued by South Africa's national Department of Basic Education (DBE) stipulates that the official aim of an HOD is "to engage in class teaching, be responsible for effective functioning of the department, and to organise relevant/related extra-curricular activities so as to ensure that the subject, learning area or phase, and the education of the learner is promoted in a proper manner" (Department of Basic Education, 2016, p. 27). While the document specifies that HODs are expected to participate in general management of the school, their supervisory role is very closely linked to teaching and learning, which is the key function of schools.

Thus, the DBE policy understands the HOD as a teacher, a subject specialist and expert, a mentor of colleagues, and a person who plays a staff development and monitoring role. Jika iMfundo's intervention with HODs is based on the premise that enhancing HODs' ability to perform their professional role and their ability to relate to teachers will build teachers' strengths, and, in turn, improve teaching and learning. The intervention sees HODs as being critical to building teachers' capacity to improve learning outcomes. Jika iMfundo identifies good practice behaviours for HODs as the following: 
- regularly checking teachers' coverage of the curriculum (curriculum tracking) and checking learners' work;

- working with teachers to improve curriculum coverage; and

- assisting teachers with problems related to curriculum coverage. (Metcalfe, 2018, p. 43)

For every teacher, the HOD has to monitor and document the following:

- Curriculum tracking, by checking whether the teacher uses the tracker (which is a document that details exactly what content and assessment teachers need to cover every day), is on track with coverage of the curriculum, and has lesson plans;

- Assessment, by checking the teacher's planned and conducted assessments;

- Supervision, by documenting each teacher's attendance at phase or departmental meetings, class visits conducted, workbooks checked as to whether or not workbooks match what is in the teacher's tracker, and number of lessons the teacher missed. (Jika iMfundo, 2015)

HODs have tools to document the above dimensions for each teacher as evidence of each of these practices. The Jika iMfundo programme is based on the belief that entrenching routine behaviours by HODs like planning, curriculum tracking of teachers and learners' work, assessment, reflection, departmental and one-on-one meetings, and working collaboratively with teachers to find solutions to problems in their department is key to improving learner outcomes.

The activities listed above reflect only some of the HOD roles that are listed in the DBE's PAM (2016) document. They do not take into account the fact that HODs are also class teachers, are responsible for the allocation of teaching loads, and undertake general school administrative tasks such as monitoring book stocks, collecting monies, and managing staff welfare as well as secretarial, and timetabling duties (PAM 2016). In short, the HOD roles gazetted by the DBE are much more comprehensive than those on which Jika iMfundo focuses.

\section{Teacher leadership}

The DBE understands HoDs as teacher leaders who assume the responsibility of facilitating professional learning for their colleagues (Nicholson, Capitelli, Richert, Bauer, \& Bonetti, 2016). Contemporary views of teacher leadership no longer see it as a preserve of school principals and administrators only. Instead, teachers at different levels in a school are viewed as having the potential to be leaders. Katzenmeyer and Moller (2009) maintain that teacher leadership is about influencing other teachers to improve their practice and adopting an attitude of lifelong learning. York-Barr and Duke (2004) define teacher leadership as a "process by which teachers, individually or collectively, influence their colleagues, principals, and other members of school communities to improve teaching and learning practices with the aim of increased student learning and achievement" (p. 287). Both these 
views point to teacher leadership as involving learning and participating in continued inquiry into practice and using student data to improve practice (Nicholson et al., 2016).

HODs are key members of school management teams and have an important role to play in providing instructional leadership and being agents of change in their departments (Dinham, 2007; Leithwood, 2016). However, there is limited research on their role in curriculum support and monitoring in South Africa. Ghavifekr and Ibrahim (2014) argue that the role of HODs includes mobilising teachers under their supervision and creating school-based communities of practice. This is line with Jika iMfundo's view on the role of HODs to provide school-based curriculum support by working with teachers, regularly checking their curriculum tracking, and assisting them with problems related to curriculum coverage through Professional Supportive Conversations.

Irvine and Price (2014) argue that professional conversations play a crucial role in professional learning communities (PLCs) to promote critical and collaborative reflection, and in transformational learning that leads to changes in practice. Dialogue and reflection also involve conversations. Senge (1990) describes "learning conversations as exposing people's thinking and making their thinking open to the influence of others" (p. 9). Salleh (2016) argues that conversations hold practice, pedagogy, and student learning under scrutiny and enable teachers to negotiate their understanding of teaching. It is therefore crucial that teacher leaders (namely, HODs) participate in professional development activities that equip them with the knowledge and skills necessary for substantive professional conversations with their colleagues.

\section{Adaptive Leadership Framework}

The Adaptive Leadership Framework (Heifetz, Grashow, \& Linsky, 2009) was adopted as the analytical framework in this study. These scholars contend that adaptive leadership "is the practice of mobilizing people to tackle tough challenges and thrive" (p. 2). They distinguish between authority and leadership and argue that leadership is a practice that draws on authority, power, and influence as tools that are critical, yet do not define leadership. Authority, they argue, is about meeting the expectations of those in power, while adaptive leadership is about challenging some of these expectations and being able to manage successfully the resistance to which this leads.

This framework distinguishes between technical and adaptive changes. Technical changes are described as simple or complex changes, often driven by external forces, which can be learned by following a series of steps. For example, learning how to use new tools such as the curriculum tracker, lesson plans, and other resources may be regarded as technical change. Technical challenges can be resolved by applying authoritative expertise and drawing on known solutions, while adaptive changes are addressed only when individuals change their beliefs, habits, and priorities, move beyond authoritative expertise, shed entrenched ways, and generate a new capacity to succeed. However, adaptive change involves creating new knowledge that will be different in different contexts. Heifetz et al. (2009) caution that 
adaptive change is time consuming, and that an adaptive leader values diversity of views and adopts an "experimental mind-set" (p. 3) to problem-solving.

Adaptive leadership focuses on change that enhances an individual's capacity to succeed and draws on previous wisdom and values. In order to practice adaptive leadership, HODs need to assist teachers in their departments to navigate through a period of disequilibrium as they distinguish between essential and expendable knowledge and solutions. This disequilibrium space is characterised by panic, confusion, frustration, and conflict, so HODs require distinct insights and skills to practice adaptive leadership and assist teachers to tolerate the discomfort. Heifetz et al. (2009) describe this space as the "productive zone of disequilibrium" (p. 18). Therefore, HODs need to address the discomfort felt by teachers and encourage them to engage with the intervention.

\section{Methodology}

This study seeks to address the following questions:

- In what ways do HODs think that Jika iMfundo training and tools enable them to better support their teachers to improve curriculum coverage or not?

- What challenges do HODs participating in Jika iMfundo face when supporting their teachers to improve curriculum coverage?

The study draws on two sources of data gathered in the Pinetown district of KZN, which has approximately 499 schools. First, a secondary analysis was conducted on existing survey data that was gathered and administered by PILO coaches, using a targeted selection of 35 schools. A total of 53 HODs completed this survey, which included questions on changes in teaching, learning outcomes, the functioning of the department, and whether curriculum coverage improved as a result of the use of Jika iMfundo tools.

The second source of data was semi-structured interviews conducted by the authors with HODs from a purposive sample of 15 schools. Schools were selected using three different criteria, namely 1) the Jika iMfundo colour classification (explained below), 2) primary or secondary schools, 3) fee-paying or no-fee schools. The selection was comprised of three primary, two combined schools (offering both primary and secondary education), and 10 secondary schools. Four of the schools are fee paying and 11 are no-fee schools. Fee-paying schools are suburban, well-resourced schools, historically administered by the House of Assembly and House of Delegates. No-fee schools are generally located in rural areas or townships and are still poorly resourced.

PILO uses the following classification to code participating schools:

- Green schools were able to demonstrate key practices without support.

- Orange schools tried to institutionalise key practices but required further direct coaching support to do so. 
- Red schools were unable to implement and/or were not trying to do so. Red schools were further categorised as schools that were stuck either because of broad functionality issues or because their staff had not undergone training. It was believed that with a catch-up process they would rapidly become orange or even green.

Of the 15 schools in this study, eight were coded orange, four were coded green, and three were coded red. All schools that were coded green are fee-paying schools, previously known as "ex-Model C" schools. Schools were selected first, and then a convenience sample of 29 HODs were interviewed, depending on who was available at the time of the research visit. The participants consisted of five primary school HODs, five combined school HODs, and 19 secondary school HODs. Ten of these HODs were novices; they had been in the position of HOD from between three and 24 months.

Table 1: Summary of schools and HODs in the sample (organised according to PILO classification)

\begin{tabular}{|c|c|c|c|c|}
\hline No & Name of School & Number and type of HODs interviewed & $\begin{array}{l}\text { PILO Colour- } \\
\text { code }\end{array}$ & $\begin{array}{l}\text { Fee-paying or } \\
\text { not* }\end{array}$ \\
\hline 1 & School A (Primary) & A1- Foundation Phase & Orange & No-fee \\
\hline 2 & $\begin{array}{l}\text { School B } \\
\text { (Primary) }\end{array}$ & $\begin{array}{l}\text { B1 - Foundation Phase } \\
\text { B2 - Grade } 2 \text { Head } \\
\text { B3 - Grade } 1 \text { Head }\end{array}$ & Orange & No-fee \\
\hline 3 & $\begin{array}{l}\text { School C } \\
\text { (Secondary) }\end{array}$ & $\begin{array}{l}\mathrm{C} 1 \text { - maths and science } \\
\mathrm{C} 2 \text { - accounting } \\
\mathrm{C} 3 \text { - humanities (languages) } \\
\mathrm{C} 4 \text { - technology }\end{array}$ & Orange & No-fee \\
\hline 4 & $\begin{array}{l}\text { School D } \\
\text { (Secondary) }\end{array}$ & $\begin{array}{l}\text { D1 - maths and science } \\
\text { D2 - language }\end{array}$ & Orange & No-fee \\
\hline 5 & $\begin{array}{l}\text { School E } \\
\text { (Secondary) }\end{array}$ & $\begin{array}{l}\text { E1 - maths and science } \\
\text { E2 - languages }\end{array}$ & Orange & No-fee \\
\hline 6 & $\begin{array}{l}\text { School F } \\
\text { (Secondary) }\end{array}$ & F1 - Deputy Principal & Orange & $\begin{array}{l}\text { Fee-paying } \\
\text { R1,500 p.a. }\end{array}$ \\
\hline 7 & $\begin{array}{l}\text { School G } \\
\text { (Secondary) }\end{array}$ & G1 - maths & Orange & No-fee \\
\hline 8 & $\begin{array}{l}\text { School H } \\
\text { (Secondary) }\end{array}$ & $\begin{array}{l}\mathrm{H} 1 \text { - maths and science } \\
\mathrm{H} 2 \text { - languages }\end{array}$ & Orange & No-fee \\
\hline 9 & $\begin{array}{l}\text { School I } \\
\text { (Combined) }\end{array}$ & $\begin{array}{l}\text { I1 - Foundation } \\
\text { I2 - Intermediate }\end{array}$ & Green & No-fee \\
\hline 10 & $\begin{array}{l}\text { School J } \\
\text { (Secondary) }\end{array}$ & $\begin{array}{l}\mathrm{J} 1-\text { science } \\
\mathrm{J} 2-\text { maths }\end{array}$ & Green & $\begin{array}{l}\text { Fee-paying } \\
\text { R33,000 p.a. }\end{array}$ \\
\hline 11 & $\begin{array}{l}\text { School K } \\
\text { (Combined) }\end{array}$ & $\begin{array}{l}\text { K1 - Senior Primary maths } \\
\text { K2 - maths and science } \\
\text { K3 - English FAL }\end{array}$ & Green & $\begin{array}{l}\text { Fee-paying } \\
\text { R19,300 p.a. }\end{array}$ \\
\hline 12 & $\begin{array}{l}\text { School L } \\
\text { (Secondary) }\end{array}$ & $\begin{array}{l}\text { L1 - maths } \\
\text { L2 - science }\end{array}$ & Green & $\begin{array}{l}\text { Fee-paying } \\
\text { R30,000 p.a. }\end{array}$ \\
\hline 13 & $\begin{array}{l}\text { School M } \\
\text { (Secondary) }\end{array}$ & M1 - maths and science & Red & No-fee \\
\hline
\end{tabular}




\begin{tabular}{|c|l|l|l|l|}
\hline 14 & $\begin{array}{l}\text { School N } \\
\text { (Secondary) }\end{array}$ & $\begin{array}{l}\text { N1 }- \text { maths and science } \\
\text { N2 - languages }\end{array}$ & Red & No-fee \\
\hline 15 & $\begin{array}{l}\text { School O } \\
\text { (Primary) }\end{array}$ & O1 - Foundation and Intermediate Phase & Red & No-fee \\
\hline
\end{tabular}

*Fee paying schools are Quintile 4 and 5 schools (previously administered by the House of Assembly or House of Delegates), and no fee schools are Quintile 1-3 (previously administered by the Department of Education and Training or the KZN Department of Education and Culture).

** Further Education and Training

\section{Findings}

We present the findings according to the two research questions.

The first research question was:

- In what ways do HODs think that Jika iMfundo training and tools enable them to better support their teachers to improve curriculum coverage or not?

There were four main themes that the HODs talked about regarding Jika iMfundo training and tools.

Jika iMfundo is useful in clarifying HOD roles

The majority of HODs in orange and red schools across both primary, secondary, and combined reported finding Jika iMfundo training very useful in clarifying the role of an HOD. Of the 29 HODs interviewed, 21 of them, all but 1 in orange and red schools, said they were not so sure of what they were expected to do as HODs before Jika iMfundo. This was particularly the case for novice HODs who had just been appointed to these positions. Of the 21 participants, 10 were new HODs, whose experience ranged from two months to three years. One of the novice HODs taught in a green school while the rest were in red and orange schools. A novice HOD had this to say:

So being a young HOD coming into management, you know ... I didn't have much experience. So, I was very fortunate that when I arrived, and, wow, here is Jika iMfundo! Before, I was not clear in understanding really what my role of function is . . you know not having the confidence you know. . So, when Jika iMfundo started, it gave me the proper training. So now I really understand my role of function as the departmental head and I have confidence in performing my duties as an HOD. I now have a plan. (Interviewee L2, Intermediate Phase HOD, green combined school)

However, even some experienced HODs reported that the Supervision Tool gave structure to what they had been doing.

Yes, it has equipped [me] with skills of managing my department. There is no training from the DBE when you become an HOD. We should get a mentor to help us, but that is not happening. But Jika iMfundo gave me insight into how to do the monitoring, 
how to ask the teachers questions in the one-on-one. (Interviewee D1, maths and science HOD, orange secondary school)

Experienced HODs also noted that the KZN Department of Education did not provide any induction programmes to newly appointed HODs, and this was seen as a serious weakness.

One thing to complement from Jika is emphasising the role of an HOD, and the role of the Deputy, etc. One of our big problems we have in our black schools is that we are promoted but we don't know actually what our role is. But no one comes to induct you and say 'Listen, this is what is happening, and this is what is expected, how you go about [it].' There is no support, [so] you don't know, no one comes and tells you. You are just promoted, and you are happy that there is money coming and you are gonna learn by the way. So, I appreciate uJika iMfundo because they have come with their modules for HODs, Module 1 and Module 6, and I appreciate that. (Interviewee N1, maths and science HOD, red secondary school)

It appeared that while the Department has paid a lot of attention to school principals and SMTs together, not enough effort has been put into equipping HODs with appropriate knowledge and skills relating to their roles as curriculum managers in their departments, and Jika iMfundo seemed to be beginning to fill this gap.

Almost all HODs from green schools (ex-Model C schools) reported that they did not find Jika iMfundo training and Tools on Supervision helpful, as reflected in the comment below.

It was compulsory for HODs to go [to Jika iMfundo training], so I attended them all. To be honest, almost nothing was useful. The format of the training was we were given the booklets and the facilitator just read through these. (Interviewee L1, science HOD, green secondary school)

However, there is some evidence that a few teachers in these schools did find aspects of the monitoring tool useful in their supervisory and monitoring roles. The science HOD from a different green school commented,

Monitoring tool was useful-I have a table to show how often I've checked books etc. (Interviewee J1, science HOD, green secondary school)

When asked how they learnt what their roles were, HODs from green schools indicated that they worked very closely with experienced HODs and that they engaged more in informal discussions than they did in formal meetings. Two of the more experienced HODs in School $\mathrm{K}$, a green school, said they attended training organised by their unions many years ago when they started as HODs. The collaborative, supportive ways of working in green schools created a conducive environment for novice HODs to learn about their roles. This kind of support was lacking in red and orange schools, and HODs in these schools relied more on Jika iMfundo to fill this gap. 


\section{Planning departmental activities}

One key tool that the majority of HODs in red and orange schools reported finding useful was the Supervision Planner and Tracker Tool (Tool 1). They mentioned that this tool allowed them to do their planning and to share their year plans with teachers.

The most useful tool is the one for supervision, and for class visits. (N1 maths HOD, red secondary school)

These HODs reported that although they did planning before, Jika iMfundo's Planning Calendar, which is part of Tool 1, brought structure to how they worked.

In terms of planning this is new, although some of it we were doing. It was not as structured and organised. (C1 maths HOD, orange secondary school)

The key advantage of the Supervision Planner and Tracker tool appeared to be the transparency it brought to the HOD's supervision practices. Where this was working, all teachers knew when each class visit and when the one-on-one visits would take place.

Because it makes you able to see teachers in different times, so it helps you to zoom in on certain teacher. So, it is planning for the year, so you are able to see the teacher . . . The teacher can see that this date is [a] departmental meeting and in this one I was monitoring all of their files, the departmental meetings. Then if I am zooming in on curriculum coverage, it would tell [an] individual teacher that on this day we would have a one-on-one. (Interviewee E1, HOD science and maths, red secondary school)

HODs in green schools reported not finding this particular tool useful, and that Jika iMfundo was not meant for schools such as these, as captured by this comment.

They [Jika iMfundo] recently 'dropped' J High. I went to the first few trainings. Mr X [principal] was worried about the time it was taking. It became clear that J High was not the target school; the coach said that and doesn't come any more. (Interviewee J2, science HOD, green secondary school)

There was consensus among HODs from green schools that they already had entrenched successful planning practices and processes and did not need Jika iMfundo's planning tools.

\section{Monitoring/tracking curriculum coverage}

Besides assisting with planning, HODs in orange and red schools found Tool 1 useful because it assisted them to monitor curriculum coverage so that they were always aware whether or not teachers were on track.

JIKA has assisted us to see whether the teachers are on par with the curriculum to see how far, for assistance. (Interviewee M1, maths and science HOD, red secondary school) 
The monitoring tool also assisted HODs to compare what they had planned with what had been done and to adapt their plans if necessary. They looked at the lessons planned against lessons conducted, as well as assessments planned against those conducted.

Trackers help us to know which work we have not done [and] are we up to date with our planning so that we [can] modify the planning accordingly. [M]aybe there are things that are disturbing the planning. (Interviewee E1, maths and science HOD, orange secondary school)

HODs also reported that Tool 1 also helped them identify teachers' weaknesses and where they needed to provide support.

It's based on curriculum tracking, that's why I appreciate this tool. Once you do curriculum tracking, you can see using the annual teaching plan, and you look at the assessments. That tool helps us [to] identify if there is a loophole because that tool has ... green, yellow and red parts, to say if the teacher is on the path to finish the syllabus or not. You ask questions and use your professional assessment to see how things go. (Interviewee N1, maths and science HOD, red secondary school)

The task of reflection was also another important aspect of the tracker that this HOD found useful.

There's reflection where teachers reflect which learners have passed or failed. Some teachers write reflections. This [is] good because it assists HODs to identify where the teacher managed or found [it] difficult to teach the topic. And as such you as an HOD get to know where to give assistance. (Interviewee N1, maths and science HOD, red secondary school)

However, HODs from the fee-paying (green) schools reported that they did not find trackers useful and therefore did not use them.

We don't use the trackers. We have our own work schedule which is more flexible. The tracker is too rigid and provides no leeway [because] it only focuses on particular textbooks. It's not suitable for our school. (Interviewee L1, maths HOD, green secondary school)

These HODs reported that they designed their own notes to use and felt that trackers were not meant for schools like theirs with well-qualified teachers. This is reflected in the statements below.

They [trackers] are very good for schools operating at a very different level.

We have qualified teachers who don't need a support like that. (Interviewee J2, maths HOD, green secondary school) 
As far as curriculum coverage, I have my own structure in place which is more explicit. The tracker does not help me at all. (Interviewee K1, HOD senior primary, green combined school)

Some felt strongly that supplying trackers to schools like theirs and expecting them to track curriculum coverage was a waste of resources.

Stop wasting money on trackers. We do not need them. You should take that money and use it for workshops. Improve education to teach in the classroom. Workshops should be based on subject knowledge on how to teach a particular topic. (Interviewee $\mathrm{K} 2$, maths and science HOD, green combined school)

It was clear that the Jika iMfundo training and tools had a more positive impact in orange and red schools, while HODs in green schools felt that they did not need support, and that Jika IMfundo should focus on schools that needed more support.

\section{Conducting Professional Supportive Conversations}

Another tool that HODs in orange and red schools found useful was the Structuring a Supervision Conversation Tool (2). They mentioned that they found training on collegial relationships and how to engage teachers in conversation about their work assisted them in improving relationships in their departments, as reflected in these statements.

We also have this kind of a form [Structuring a Supervision Conversation Tool] which is for the meetings. It's a guide on the one-on-one meeting. This helps . . . [so] the teacher doesn't become defensive. It's just an instrument to help teachers . . . because they were saying HODs end up not having one-on-one meetings because in those meetings, it becomes difficult ... So, for us to be able to hold those meetings they gave us a guide in terms of how to approach the curriculum coverage, [to see] if the teacher is lagging behind. (Interviewee E2, HOD languages, orange secondary school)

The one-on-one meetings improved relationship with teachers, and we work with them as a team. (Interviewee B3, Foundation Phase HOD, orange primary school)

When asked how the teachers found these conversations, the majority of HODs responded that their discussions were fruitful. This was confirmed by the survey data where HODs reported that the one-on-one sessions "allow teachers to open up when they need help", assisted them to "conduct non-judgemental meetings . . . this removes feelings of shame and discomfort", "eliminates fear and tensions, encourages co-operation and openness", and "improved conversations about what happens in the classroom." This seems to indicate that the conversations enabled HODs to address the personal dimension of their supervisory role and recognise the importance of acknowledging teacher's emotions in their practice.

However, one of the HODs in an orange school reported finding one-on-one conversations difficult when dealing with a teacher who teaches a subject different from his. 
I'm not the expert in all the subjects, [so] I have to bring in a subject head, and sometimes the subject head will collude with the teacher. So, the subject head comes to observe the lesson, and then we have the PLC with the subject head. Sometimes it can be difficult [being] the one [who is] not the expert in the subject. (Interviewee D1, science and maths HOD, orange secondary school)

This highlights the power dynamics and consequent complexities in conducting one-on-one Professional Supportive Conversations.

In line with their views on the other tools, HODs in green schools, said they did not conduct one-on-one meetings, but engaged in regular informal departmental discussions, as reflected here:

We don't have formal one-on-one meetings. I'm the youngest in the department, so I prefer to keep them informal. We have WhatsApp groups and an informal ethos, where we can discuss issues regularly. (Interviewee L1 maths HOD, green secondary school)

Again, the data shows the difference between no-fee and fee-paying schools in that the collegial support envisaged by official policy is already evident in the fee-paying schools.

The second research question was:

- What challenges do HODs face when supporting their teachers to improve curriculum coverage?

This section describes the three key challenges that HODs said they encounter when supporting their teachers to improve curriculum coverage; these are, essentially, all related to time.

\section{Too much paperwork: "Paperwork ahead, child is behind"}

It is very clear from all the interview data as well as from the survey data, that the HODs feel that there are simply too many monitoring tools that need to be used. This is particularly true for HODs who supervise many teachers, sometimes across a range of subjects.

At School D (a high school with 1481 learners and 49 teachers), the maths and science HOD (D1) has 15 teachers in his department. He said: "It's too much with IQMS, moderation of assessment, pre-moderation, post-moderation. I have 13 papers that I must moderate for these exams." He is also the grade 12 maths teacher. He noted that to complete the Jika iMfundo monitoring tasks was simply too burdensome. He felt that Jika iMfundo assumes that all departments are the same size, with an HOD to teacher ratio of about 1 to 4 or 5. However, this is not true of big schools.

At School B, an orange primary school, there is only one HOD for the Foundation Phase with five teachers per grade, so the principal appointed a senior teacher in Grades 1 and 3 to help 
with the administrative monitoring work of Jika Imfundo. All three teachers whom we interviewed at this school said that there is simply too much paperwork and HOD B2 said there were too many files that needed to be kept (management file, supervision file, assessment file, staff development files). Participant B1 noted that when "Paperwork is ahead, child is behind."

In School I, the Intermediate phase HOD was supervising 16 teachers without any help. Since the HOD is also teaching a class, this administrative task is simply too onerous for a single person.

The maths HOD at School J (a high school with 1,100 learners) notes, similarly: "The volume was unrealistic. They [Jika iMfundo] wanted me to meet with each teacher twice a term, take minutes, keep a file, talk about their strengths and weaknesses. I have 14 teachers who teach maths. It's just impossible."

Some HODs also noted that there were tensions between the requirements of the Department and Jika iMfundo, which also led to more administrative work. An HOD at School C (orange secondary school) noted "We end up having more work and we end up being under pressure, having to use two tools, because we have the Jika tools, but the other is the real one, the one for work [that is, for the Department] . . Although Jika wants it this way, sometimes the Subject Advisors want it in a different way."

Challenges with sequencing and pacing of the curriculum trackers: "It is only for high fliers"

Another challenge raised by all the HODs in the interviews and corroborated by the survey data was the concern that the trackers take a one-size-fits-all approach to curriculum coverage. Participants raised two issues regarding the trackers; the first is that the pace is too fast and thus does not cater for differences among learners; and the second has to do with the sequencing of the topics (particularly in maths).

Sequencing refers to the order in which the topics and tasks are set. Pacing refers to how quickly or slowly the topics in the curriculum need to be covered. In the Curriculum Assessment Policy Statements (CAPS), pacing is strongly framed, which means that the teachers do not have much leeway to change it (Pausigere, 2016). Since the Jika iMfundo trackers are based on CAPS, the prescribed pacing of lessons is also fast. The Jika iMfundo Planner and Trackers make it clear that teachers need to follow the prescribed sequencing and pacing. The following excerpt is from the Grade 12 maths Planner and Tracker, but this is mentioned in all the trackers.

The content in each tracker has been carefully sequenced and it is therefore important that lessons are not skipped. Should you miss a Mathematics lesson for any reason, or should you be going at a slower pace, you should continue the next day from where you last left off. Do not leave a lesson out to get back on track. You may need to 
speed up the pace of delivery to catch up to the lesson schedule - by covering the lesson concept content of two consecutive days in one day (PILO, 2017, p. 3).

HODs have the task of supporting their teachers to achieve curriculum coverage. However, the fast pace of the curriculum means that meaningful coverage is not possible. In order to achieve curriculum coverage, the trackers require teachers to move on despite some learners not understanding the concepts, and it becomes the teachers' responsibility to help learners catch up after school.

In order to support the learners who "do not get it" in class, the teachers at many schools (Schools B, C, D, F, J, and L) noted that they run remedial classes before or after school a few times a week. The maths HOD at School D (orange secondary school) said, "If they don't finish, you must catch up with extra classes every week. In the senior grades, you may have three extra lessons per week in the morning or afternoon. Some of the learners are slow to grasp the content. We are told to move with the Annual Teaching Plan (ATP). In maths, only $30 \%$ [of learners] are at the pace of the ATP; it is only for high fliers."

Participant B2 noted a concern with both the pacing and the sequencing.

... especially in maths, you sometimes find that there are so many concepts in one lesson, such as addition, subtraction, sharing ... (division). So, the slow learners cannot catch up easily, they are always left behind. Furthermore, on each and every day the teacher has to start a new lesson. For the slow learners they find it difficult to catch up. Ya. It tends to show that Jika iMfundo is only for the high fliers, not for slow learners. It's no longer learner paced. (Interviewee B2, Grade 2 HOD, orange primary school)

The Foundation Phase participants in School I and B were concerned that the lesson plans covered too many different maths concepts in one lesson and did not allow enough time for the consolidation of learning. Many other participants also noted that there are too many activities in one lesson.

These HODs seemed to be unaware that they did not have to use all the listed activities. The trackers note that teachers should make "the final professional choice about which examples and explanations to give, which activities to set for [their] class and how to manage [their] class on a daily basis." (Grade 12 Mathematics Tracker, p. 4)

Teachers at some schools interrogate the tools and adjust them to fit their context. All the HODs from the green schools in our sample (Schools J, K, and L) engaged with the tools in a very flexible way, changing them when necessary to suit the school context, or they did not use them at all, finding them too rigid and undermining of teachers' creativity according to the science HOD from School L. He finds that the CAPS document and assessment guidelines provide enough detail about what needs to be covered, and they make their own notes for learners. 
Many HODs in the orange and red schools said that this pacing challenge is compounded by the Departmental progression policy which stipulates that no learner can spend more than four years in one phase. Thus, if a child has failed one grade in a phase, she or he cannot fail again, and will be progressed automatically to the next grade. The maths HOD in School C (orange secondary school) was clear that simply covering the curriculum did not lead to quality learning.

This focus on the curriculum coverage does not portray the actual situation or quality. Just covering the work only does not portray the quality of the work. At the end of the day, the "progressed" learner moves to another class ... The teachers follow the tracker and leave a lot of students behind. (Interviewee C1, maths HOD, orange secondary school)

\section{Contextual challenges: "The tracker is designed for perfect schools"}

Conditions in schools that are beyond the HOD's control also have an impact on curriculum coverage. Many HODs noted that the Jika iMfundo trackers do not take these contextual factors into account. These contextual challenges relate to material resources in a school, such as a lack of textbooks or a lack of water; organisational use of time and teacher absenteeism; departmental policies (such as the progression policy and the Post Provisioning Norm); learners' readiness and motivation to learn; and the heavy administrative requirements of the HOD role.

An HOD from a secondary school noted, "There are no textbooks in the GET phase, as the principal seems to buy only for the FET phase. So, the teacher must spend considerable time photocopying pages for the 70 learners in the Grade 8 and 9 classes." (Survey data). At school M, a red secondary school, the material resource that was absent was water; this causes huge disruptions to the learning and teaching time because the school day inevitably ends early.

An English First Additional Language HOD from a red secondary school noted that "the tracker is designed for perfect schools with no disruptions" (survey data). A number of participants in the survey and the interviews expressed the same opinion, noting that the trackers assume that teaching and learning is happening on every day of the school year, with no teacher absenteeism or other disruptions. This is obviously the goal of Jika iMfundo, since the issue of lost teaching time and minimal opportunity to learn has been raised by a number of studies (Hoadley, 2013; Taylor, 2009). However, it appears that the trackers hope to solve the problem by assuming that it does not exist; the trackers do not allow for flexibility or any kind of catch-up time. This puts huge pressure on teachers to make up teaching time lost because of disruptions. Some of these disruptions, such as teacher absenteeism and attendance at South African Democratic Teachers Union (SADTU) meetings, implicate teachers, but are still outside the control of the HOD. For example, on the day of our research visit to school N (red secondary school), teachers were all leaving early to attend a Heritage Day cultural celebration organised by SADTU. 
Another challenge outside of HODs' control relates to the departmental policies of Post Provisioning Norms (PPN) and of the progression of learners. An HOD in School C noted that "learners are now leaving our black schools" which means that the number of teachers decreases since the PPN allocates teachers to schools according to the number of enrolled learners. The progression policy means, as mentioned above, that learners who have failed one grade in a phase will automatically progress. One HOD noted that "some of these progressed kids are not interested [in learning] ... they tell us that we cannot fail them." (Interviewee C1, maths HOD, orange secondary school)

This links to a further challenge raised by HODs - the learners' capacity and motivation to learn. One HOD noted in the survey that "the tracker has an assumption that when you teach a learner s/he understands the content without challenges." The reality is that $60 \%$ of South African children have not learnt to read for meaning by the end of Grade 3 (van den Berg, 2015) and thus "never fully access the curriculum despite being promoted to higher grades" (van den Berg, Spaull, Wills, Gustafsson, \& Kotze, 2016, p. 6). Similarly, maths achievement is low, as shown in the Trends in International Mathematics and Science study (TIMMS) and Annual National Assessments (ANA) results (van den Berg, 2015). The HODs point out that the pacing of the trackers does not take this huge challenge into account, but seems to assume that all the learners are "high fliers," However, for many learners "the fundamentals are not in place" (Interviewee K3, English First Additional Language HOD, green combined school), making it impossible to cover the curriculum at the required pace, and still ensure that every learner has understood the concepts.

Many HODs in the red and orange schools reported that they have to fulfil a huge range of administrative tasks that are not directly related to teaching and learning. For example, HODs have to monitor attendance of both teachers and learners, attend to learner discipline issues, enter learner marks on the Schools Administration and Management System (SAMS) data base, sit on a range of school committees such as the bereavement committee, cultural committee, and so on. The fee-paying ex-Model C schools employ additional staff to fulfil some of these tasks. For example, School J (green secondary school) employs a person whose sole job is to monitor learner attendance and attend to discipline issues, as well as employing additional administrators who capture marks.

Again, the data points to the differences between historically white and black schools which has an impact on the HODs' capacity to fulfil their roles and support the staff in their departments.

\section{Discussion}

This section summarises the main findings related to the research questions and then uses the concept of adaptive leadership to explain and interrogate these findings. There are three main findings that support our argument that the history and context of schools influence the way in which HODs can fulfill their tasks. 
The first main finding is that many HODs in the orange schools noted that their participation in Jika iMfundo has resulted in more regular (routine) meetings with the staff in their departments, improved curriculum coverage, improved relationships within the department and enhanced confidence regarding their own role as an HOD. HODs said that they did engage in professional conversations with their staff and they reflected to a greater extent on curriculum coverage and, to a lesser extent, on student learning and their own practice.

Many HODs in the orange schools found the training and the tools very helpful in understanding what their task as an HOD entails and helping them to plan for the year ahead. In particular, novice HODs grew in confidence and appreciated the new knowledge and skills acquired on how to manage and lead their departments. They had not received this knowledge or these skills from their school or the DBE previously. In contrast, the HODs in green schools all said that they did not need the training or the tools since they already felt confident in performing their HOD roles, had the support of their colleagues and school management team, and already had a range of functional planning tools and practices in place. These schools have greater organisational capacity and human and physical resources than many of the no-fee schools.

The second finding is that time and school context are major constraints in HODs' ability to track and support curriculum coverage in their departments. HODs from all schools are unanimous that the monitoring tools and trackers are simply too burdensome to complete as Jika iMfundo envisages. The workload carried by HODs is either heavy or very heavy, depending on the administrative challenges resulting from their school context and the numbers of teachers in their departments. Many HODs mentioned that it was not possible to hold one-on-one conversations as frequently as Jika iMfundo recommends because they have too many teachers in their departments. HODs in green schools responded to this challenge by simply not using the Jika iMfundo tools and engaging instead in supportive collegial departmental meetings. Other contextual factors in red and orange schools like the lack of textbooks, lack of water, teacher absenteeism, the (mis)use of time, learners' readiness (or the lack of it) to learn, and the progression policy hinder the HODs' ability to play the supportive developmental role envisaged in the PAM document and by Jika iMfundo.

The third finding is that HODs in orange and red schools tend to take a more technical approach to their HOD role; this favours the monitoring rather than the support aspect of it. HODs have an understanding of their three roles as outlined by Jika iMfundo-monitoring teachers' curriculum coverage and learners' work, supporting teachers to improve curriculum coverage, and assisting teachers with problems related to curriculum coverage. However, findings suggest that they focus predominantly on the first role of regularly checking teachers' curriculum trackers and to a lesser extent on the other two roles.

Using the Adaptive Leadership Framework (Heifetz et al., 2009), we suggest that HODs in the orange and red schools are leading their departments from a technical position of authority rather than an adaptive one. At a technical level, it appears that HODs are following the requirements of the curriculum trackers, learner monitoring tools, and supervision tools, all of which are externally regulated by the DBE Subject Advisors and by the Jika iMfundo 
coaches. The HODs were aware that some teachers simply completed the forms to "cover their heads" but felt that there was not much that they could do about it, given the contextual constraints and huge administrative burden.

Jika iMfundo hopes that HODs will move to a level of adaptive change, which means that they should want to move from a compliance approach to a more developmental approach to supervision which is "characterized by reflection, learning, behavioural change and improved teaching practice" (Module 2, p. 11). However, the HODs in the orange and red schools were simply trying to "keep their heads above water" and manage all the competing demands on their time. Taking a technical approach is the best they can do under very trying circumstances. It is unlikely that HODs will move to a more adaptive level of leadership unless the heavy administrative workloads required of them, the strong pacing of the curriculum, and the heterogenous nature of learners' cognitive competences is addressed (Schollar, 2018)

The HODs in the green ex-Model $\mathrm{C}$ schools seemed more likely to practice adaptive leadership. This practice reflects their professional confidence supported by their school context that has a flatter organisational model evidenced by greater collaboration and support among teachers. These schools also have more human resources and a more complex division of labour (Harley, Mattson, Bertram, Barasa, \& Pillay, 2000), such as grade controllers who focus on discipline issues, and administrative staff who capture marks. This allows HODs to focus more on academic issues of teaching and learning and provide more support to novice HODs. The resources in these schools enable the HODs to exercise more personal agency and provide greater support to their teachers. There is more evidence of reciprocal accountability (Elmore, 1996) in green schools since HODs are playing a more developmental role rather than merely a compliant supervisory one. Green schools already have the organisational and planning capacity and collegial supportive practices that Jika iMfundo is aiming to develop.

\section{Conclusion}

This study shows that the training and tools provided by Jika iMfundo are helpful for many HODs in the orange and red schools. However, their ability to play a supportive and developmental role is constrained by the lack of time and contextual challenges in their schools. HODs occupy a fluid space that locates them at the interface of teaching, management, and leadership, and are expected to juggle all responsibilities associated with these roles. This explains, possibly, some of the challenges regarding the HODs' abilities to play an adaptive transformative leadership role in improving curriculum coverage successfully as envisaged by Jika iMfundo. This tension is more evident in red and orange schools with weak organisational capacity characterised by, among other things, limited administrative support. The Jika iMfundo programme seems to over-estimate the power that HODs have as agents of change. They are middle managers who are held responsible and accountable to implement policy and ensure curriculum coverage but have minimal resources 
and decision-making power to assist them in these roles. These findings demonstrate the need for ongoing middle management research in South African schools.

\section{Acknowledgement}

Data collection for this study was funded by the South African Institute of Distance Education (SAIDE). An earlier version of this article appears in Christie and Monyokolo (2018).

\section{References}

Christie, P., \& Monyokolo, M. (Eds.). (2018). Learning about sustainable change in education in South Africa: The Jika iMfundo campaign 2015-2017. Johannesburg, RSA: SAIDE.

Department of Basic Education. (2016). Personnel Administrative Measures. Government Gazette, No. 39684. Pretoria, RSA: Government Press.

Dinham, S. (2007). How schools get moving and keep improving: Leadership for teacher learning, student success and school renewal. Australian Journal of Education, 51(3), 263-275. https://doi.org/10.1177/000494410705100304

Elmore, R. F. (1996). Getting to scale with good educational practice. Harvard Educational Review, 66(1), 1-26.

Ghavifekr, S., \& Ibrahim, M. S. (2014). Head of departments' instructional supervisory role and teachers' job performance: Teachers' perceptions. Asian Journal of Social Sciences and Management Studies, 1(2), 45-56.

Hargreaves, A. (2001). Emotional geographies of teaching. Teachers College Record, 103(6), $1056-1080$.

Harley, K., Mattson, L., Bertram, C., Barasa, F. and Pillay, K. (2000). The real and the ideal: Teacher roles and competences in South African policy and practice. International Journal of Educational Development, 20(4), 287-304. https://doi.org/10.1016/S07380593(99)00079-6

Heifetz, R., Grashow, A., \& Linsky, M. (2009). The theory behind the practice: A brief introduction to the adaptive leadership framework. Boston, MS: Harvard Business.

Hoadley, U. (2013). What do we know about teaching and learning in South African primary schools? Education as Change, 16(2), 187-202. https://doi.org/10.1080/16823206.2012.745725 
Irvine, S. \& Price, J. (2014). Professional conversations: A collaborative approach to support policy implementation, professional learning, and practice change in ECEC. Australian Journal of Early Childhood, 39(3), 85-93. https://doi.org/10.1177/183693911403900311

Jika Imfundo (2015). Effective curriculum supervision: Building relationships to improve learning. Module 2 (HOD): A training manual. KwaZulu-Natal Department of Education and National Education Collaboration Trust.

Katzenmeyer, M., \& Moller, G. (2009). Awakening the sleeping giant: Helping teachers develop as leaders (2nd ed.). Thousand Oaks, CA: Corwin Press.

Leithwood, K. (2016). Department-head leadership for school improvement. Leadership and Policy in Schools, 15(2), 117-140. https://doi.org/10.1080/15700763.2015.1044538

Metcalfe, M. (2018). Jika iMfundo 2015-2017: Why, what and key learnings. In P. Christie \& M. Monyokolo (Eds.), Learning about sustainable change in education in South Africa: The Jika iMfundo campaign 2015-2017 (pp. 17 -74). Johannesburg, RSA: Saide.

Nicholson, J. C., Capitelli, S., Richert, S., Bauer, A., \& Bonetti, S. (2016). The affordances of using a teacher leadership network to support leadership development: Creating collaborative thinking spaces to strengthen teachers' skills in facilitating productive evidence-informed conversations. Teacher Education Quarterly, 43(1), 29-50.

Pausigere, P. (2016). On Bernstein's sociology of pedagogy and how it can inform the pedagogic realisation of poor and working-class children in South African primary maths education. Educational Research for Social Change, 5(1), 41-53. http://dx.doi.org/10.17159/2221- 4070/2016/v5i1a3

Programme to Improve Learning Outcomes (PILO) (2017) Grade 12 Mathematics Teacher Toolkit. Planner and Tracker. Centurion, RSA: National Education Collaboration Trust.

Salleh, H. (2016). Facilitation for professional learning community conversations in Singapore. Asia Pacific Journal of Education, 36(20), 285-300. https://doi.org/10.1080/02188791.2016.1148855

Schollar, E. (2018) Curriculum management, improving learner performance and the rise of multi-grade classes: A tangled web of challenges to the design, operation and evaluation of educational development programmes in South Africa. In P. Christie \& M. Monyokolo (Eds.), Learning about sustainable change in education in South Africa: The Jika iMfundo campaign 2015-2017 (pp. 99-124). Johannesburg, RSA: Saide. 
Senge, P. (1990). The fifth discipline: The art and practice of the learning organization. New York, NY: Currency Doubleday.

Taylor, N. (2009). The state of South African schools Part 1: Time and regulation of consciousness. Journal of Education, 46, 9-32.

van den Berg, S. (2015). What the Annual National Assessments can tell us about learning deficits over the education system and the school career. South African Journal of Childhood Education, 5(2), 28-43.

van den Berg, S., Spaull, N., Wills, G., Gustafsson, M., \& Kotze, J. (2016). Identifying binding constraints in education. Synthesis report for the Programme to Support Propoor Policy Development (PSPPD). Stellenbosch University, RSA: Research on Socio-Economic Policy. http://doi.org/10.3102/00346543074003255

York-Barr, J., \& Duke, K. (2004). What do we know about teacher leadership? Findings from two decades of scholarship. Review of Educational Research, 74(3), 255-316. 